\title{
Indoor noise measurements evaluations for HVAC-Unit using inter-laboratory comparisons
}

\author{
H.S. Seddeq ${ }^{1, \star}$ and A.A. Medhat A. Fahim ${ }^{2}$ \\ 1 Associate Professor of the Acoustic Laboratories in Building Physics Research Institute at Housing and Building National \\ Research Center, HBRC, P.O. Box 1770 Giza, Cairo, Egypt \\ 2 Associate Professor, HVAC Consultant in Electro-Mechanical Research Institute at Housing and Building National Research \\ Center, HBRC, P.O. Box 1770 Giza, Cairo, Egypt
}

Received: 7 December 2010 / Accepted: 24 November 2011

\begin{abstract}
The international standard, ISO/IEC 17025 was developed to determine technical competence and to evaluate laboratories throughout the world. Accreditation bodies playing a vital role are increasingly using proficiency testing methodology as a tool to ensure the credibility of their accreditation programs. The successful completion of a well-designed proficiency test can validate the measurement method and uncertainty budgets of a testing laboratory. Additionally, proficiency tests can provide a good indication about the quality of the test results. An important part of inter-laboratory comparisons and proficiency testing is the determination of the associated error analyses which are focused on uncertainty values. This paper presents the implementation of proficiency tests using inter-laboratory methodology among five different acoustic laboratories. These tests were carried out on $5.27 \mathrm{KW}_{\text {Cooling standard unitary air }}$ conditioner, A/C, such as through-wall or split room standard A/C units, for the assessment of Housing \& Building National Centre acoustic laboratory. Analyses of results show a good agreement for $E_{n}$-Value among the selected laboratories when compared with the lowest uncertainty as stated by proficiency tests standards.
\end{abstract}

Keywords: Indoor sound measurements; noise level in dBA; air-conditioning unitary unit; proficiency testing; Uncertainty; ISO/IEC 17025; ASTM 1574

\section{Introduction}

For noise control in buildings a set of criteria for the acoustic performance of building has to be established in order to fulfill acoustic comfort conditions indoors. In the case of a field evaluation of measurement of heating and ventilating air-conditioning systems (HVAC) noise in rooms, the uncertainty must be evaluated and added to the final result to be compared to a specified noise criterion rating system such as dBA, NC, RC, or NCB. The housing and building national research centre (HBRC) in Egypt is encouraged that tests in the field of building acoustics should have accreditation according to the standard ISO/IEC 17025. For assuring the quality of test results, the laboratory shall have quality control procedures for monitoring the validity of tests. Statistical techniques shall be applied to the reviewing of the results such as participation in inter-laboratory comparison or proficiencytesting programs [1]. Therefore the building acoustics lab in HBRC should perform a complete evaluation of uncertainty and proficiency tests. One of these tests that have to

${ }^{\star}$ Correspondence: hodasoliman@yahoo.com be accredited is the indoor noise measurements of HVAC systems according to ASTM 1574. The Assessment for HBRC building acoustic laboratory has been carried out by International Accreditation Service, IAS.

For laboratories seeking accreditation to ISO/IEC 17025 , they shall apply a procedure to estimate the uncertainty of measurement according to Section 5.4.6 of ISO/IEC 17025 [1]. ISO defines measurement uncertainty $(\mathrm{MU})$ as a parameter associated with the result of a measurement that characterizes the dispersion of values that could reasonably be attributed to the measurand. For a test sample, the true value of the measurand is never known. The ISO definition implies that a test result, effectively a range when the estimated MU is taken into account, will encompass the true result. The probability that this will be so, depends on the level of confidence provided by the estimate of MU. Most commonly, an expanded uncertainty is estimated by applying a coverage factor to provide a level of confidence of approximately $95 \%$. There are a number of different approaches to estimating MU. These include the fundamental metrological approach described in the ISO guide to the expression of uncertainty in measurement $[1,2]$. 


\section{Assessing accuracy of results}

As part of their quality assurance programs, accreditation bodies normally require accredited laboratories to participate in proficiency testing where each participating laboratory test the same specimen or sample. The purpose of proficiency testing is to ensure that the participating laboratories can make reliable measurements. It can contain a blunder or other serious error, which makes it atypical for what would be expected from the laboratory, or the uncertainty of the measurement can be underestimated, such that the error in a correctly performed measurement is larger than the uncertainty stated by the laboratory. A measure of the quality of the design of a proficiency test is how well it can distinguish between reliable and unreliable measurements. The width of the gray zone between reliable and unreliable measurements as judged by the proficiency test can be thought of as the uncertainty of the proficiency test. To minimize the uncertainty of the proficiency test it is necessary to have a reference value that is reliable and has a low uncertainty $[3,4]$.

ISO/IEC 17043 [5] gives two basic measures for evaluating the results of proficiency testing. One of these measures is the $E_{n}$-value that is the most suitable measure for inter-laboratory comparisons. The $E_{n}$-value approach requires each laboratory to report an uncertainty. $E_{n}$-value can be calculated as follows [5]:

$$
E_{n}=\frac{\text { Value }(\text { lab })-\text { Value }(\text { Ref })}{\sqrt{U(l a b)_{95}^{2}+U(\operatorname{Ref})_{95}^{2}}}
$$

$\operatorname{Value}(l a b)$ is the value reported by the participating laboratory;

$\operatorname{Value}(R e f)$ is the reference value for the measure and;

$U(l a b)_{95} \quad$ is the uncertainty reported by the participating laboratory;

$U(R e f)_{95} \quad$ is the uncertainty of the reference value.

Results are judged as follows [5]:

$--1.0 \leq E_{n} \leq 1.0$ is satisfactory

- $E_{n}>1.0$ or $E_{n}<-1.0$ is unsatisfactory.

An important part of inter-laboratory comparisons and proficiency testing is the determination of the reference value of the measurand and the associated uncertainty. It is desirable to have reference values with low uncertainty, but it is crucial that these values are reliable, i.e. they are correct within their stated uncertainty. In some cases it is possible to obtain reference values from laboratories that can reliably produce values with significantly lower uncertainty than the proficiency testing participants [4].

The repeatability $r$ is the value below which the absolute difference between two single test results obtained under repeatability conditions that may be expected to lie with a probability of $95 \%$. The repeatability value $r$ can be determined as follows [6]:

$$
r=2.8 \sqrt{s_{r}^{2}}
$$

Where $s_{r}$ is the repeatability standard deviation under repeatability conditions for mutually independent test results. The repeatability value $r$ can obtained with the same method on identical test material in the same laboratory with the same equipment by the same operator.

Reproducibility value, $R$ is a parameter of dispersion of the distribution of test results under reproducibility conditions where test results can be obtained with the same method on identical test sample in different laboratories with different operators using different equipment. Reproducibility value, $R$ may be expected to lie with a probability of $95 \%$. Reproducibility value $R$ can be determined as follows [6]:

$$
R=2.8 \sqrt{s_{R}^{2}}
$$

Where $s_{R}$ is the standard deviation of test results obtained under reproducibility conditions.

\section{Experimental work}

The HBRC organized proficiency-testing program in order to assure the quality of measuring indoor steady sound pressure level for HVAC unit to evaluate the test competence of HBRC acoustic laboratory. 5 partners from Egypt participated in the proficiency test; the participants' information is given in Table 1 . All equipments of the participating laboratories have been calibrated in accredited laboratory for acoustics.

\subsection{Description of test sample}

The air conditioning window-unit of capacity $5.27 \mathrm{~kW}_{\text {Cooling }}$ installed in office room no $\mathrm{R} 2-5$ th floor in HBRC. The unit mounted at the middle of the east side wall. The distance vertical from the center of the unit and the floor is $1.5 \mathrm{~m}$. The volume of the room is $75 \mathrm{~m}^{3}$. The floor area of the room is $20 \mathrm{~m}^{2}(5 \mathrm{~m} \times 4 \mathrm{~m})$. There are two wooden tables, metal cupboard for books and 4 hard chairs. The internal surfaces were painted by cementitious material and the floor is covered with vinyl tiles. Ceiling metal tiles of perforation $20 \%$ with thin PVC black layer and rock wool layer of thickness $25 \mathrm{~mm}$ and density $50 \mathrm{~kg} / \mathrm{m}^{3}$ are installed over the room. The room has a $3.5 \mathrm{~m} \times 2 \mathrm{~m}$ glass window.

\subsection{Measurements procedure}

The measurements method was carried out according to ASTM E 1574 and ASHRAE recommended procedure for measuring the HVAC System - Induced Noise in a Room $[7,8] .5$ participants measured the noise of the air conditioning window-unit using the same measurements procedure. The measurements conducted with the room vacated by occupants at midnight after the employees left the building. The window was closed during the test and all non HVAC equipment was turned off. All tests were carried out on July 10/ 11/2010. The microphone was $1.3 \mathrm{~m}$ above the floor. The microphone was located at a distance greater than $1 \mathrm{~m}$ to any wall or other extended surface. Each sound level meter was connected with the microphone and was calibrated by its compatible calibrator. The measured A-weighted sound pressure levels, was 
Table 1. Participant laboratories for HBRC acoustic lab proficiency test.

\begin{tabular}{|c|c|c|}
\hline Participant & Instrumentation & Measurement location \\
\hline $\begin{array}{l}\text { National Institute } \\
\text { for Standards NIS } \\
\text { in Egypt }\end{array}$ & $\begin{array}{l}\text { Sound level meter type } 2260 \text { - sound analysis } \\
\text { software type } 7210-1 / 2 \text { inch electric condenser } \\
\text { microphone - type } 4189(\mathrm{~B} \& \mathrm{~K}) \text { - microphone } \\
\text { preamplifier ZC-0026 - calibrator } 4231 \text { (B\&K) }\end{array}$ & $\begin{array}{l}1.25 \mathrm{~m} \text { from the } \\
\text { source }-2 \mathrm{~m} \text { from } \\
\text { side wall }\end{array}$ \\
\hline $\begin{array}{l}\text { Housing and } \\
\text { Building National } \\
\text { Research Center } \\
\text { HBRC }\end{array}$ & $\begin{array}{l}\text { Sound level meter type } 2270 \text { - sound analysis } \\
\text { software BZ-7223 - } 1 / 2 \text { inch electric condenser } \\
\text { microphone type } 4189(\mathrm{~B} \& \mathrm{~K}) \text { - microphone } \\
\text { preamplifier ZC-0032 - calibrator } 4231 \text { (B\&K) }\end{array}$ & $\begin{array}{l}1.20 \mathrm{~m} \text { from the } \\
\text { source }-2.10 \text { from } \\
\text { the side wall }\end{array}$ \\
\hline Luukki & $\begin{array}{l}\text { Precision handheld sound analyzer Nor140 - } \\
2 / 1 \text { microphone Nor1225 and preamplifier } \\
\text { Nor1209 - calibrator type Nor- } 1253\end{array}$ & $\begin{array}{l}1.17 \mathrm{~m} \text { from the } \\
\text { source }-2.12 \text { from } \\
\text { the side wall }\end{array}$ \\
\hline Hmam & $\begin{array}{l}\text { Sound level meter type RION NA-28 } 1 / 2 \\
\text { Condenser microphone UC } 59 \text { preamplifier NH } 23- \\
\text { Pistonphone calibrator Rion NC-72 }\end{array}$ & $\begin{array}{l}1.31 \mathrm{~m} \text { from the } \\
\text { source }-2 \mathrm{~m} \text { from } \\
\text { the side wall }\end{array}$ \\
\hline $\begin{array}{l}\text { Acoustic lab of } \\
\text { Egypt-cooling }\end{array}$ & $\begin{array}{l}\text { Sound level meter type } 2250(\mathrm{~B} \& \mathrm{~K}) \& \text { BZ } 7223- \\
\text { Frequency Analysis Software }-1 / 2 \text { inch electric } \\
\text { condenser microphone type } 4189(\mathrm{~B} \& \mathrm{~K})- \\
\text { Microphone Preamplifier ZC-0032 - calibrator } \\
\text { type } 4231(\mathrm{~B} \& \mathrm{~K})\end{array}$ & $\begin{array}{l}1.35 \mathrm{~m} \text { from the } \\
\text { source }-2 \mathrm{~m} \text { from } \\
\text { the side wall }\end{array}$ \\
\hline
\end{tabular}

Table 2. Guidelines for determining equipment sound levels in presence of contaminating background noise.

\begin{tabular}{cc}
\hline $\begin{array}{c}\text { Measurement A minus } \\
\text { Measurement B }\end{array}$ & $\begin{array}{c}\text { Correction to measurement A } \\
\text { to obtain equipment sound level }\end{array}$ \\
\hline $10 \mathrm{~dB}$ or more & $0 \mathrm{~dB}$ \\
6 to $9 \mathrm{~dB}$ & $-1 \mathrm{~dB}$ \\
4 to $5 \mathrm{~dB}$ & $-2 \mathrm{~dB}$ \\
$3 \mathrm{~dB}$ & $-3 \mathrm{~dB}$ \\
$2 \mathrm{~dB}$ & $-4 \mathrm{~dB}$ \\
$1 \mathrm{~dB}$ & $-7 \mathrm{~dB}$ \\
$0 \mathrm{~dB}$ & Equipment sound level is at least \\
& 9 dB below Measurement A
\end{tabular}

Measurement $\mathrm{A}=$ Tested equipment plus background noise. Measurement $\mathrm{B}=$ Background noise alone.

the steady sound whose pressure level remains substantially constant during the period of observation when measured with the slow setting on the sound level meter. The period of $40 \mathrm{~s}$ was selected for each measurement [7]. Each participant surveyed the sound pressure level measurements in the space to define the point at which the highest utilities-generated A-weighted slow response sound level occurs was located. Each participant repeated the measurements 10 times at this point and took the average A-weighted sound levels [7]. The octave band sound pressure level in each band from $31.5 \mathrm{~Hz}$ to $8000 \mathrm{~Hz}$ was also measured.

The background noise levels were measured where HVAC equipment was turned off. Then the A-weighted octave band sound pressure level in each band from $31.5 \mathrm{~Hz}$ to $8000 \mathrm{~Hz}$ was measured. The measured noise level with the HVAC system turned on, may be adjusted to artificially remove the effects of ambient noise. The ambient noise correction is made independently on an octave basis. This correction is given in Table 2 that helps to determine the HVAC sound level in the presence of background noise [9]. Table 1 shows the defined points locations of the five participating laboratories.

\subsection{Uncertainty components for indoor sound pressure level of HVAC-Unit}

Considering a situation where an integrating sound level meter is used, one performs $n \mathrm{~A}$-weighted slow response steady sound level measurements $L_{A 1} . L_{A 2} \ldots L_{A i} \ldots L_{A n}$ during reference time intervals $(40 \mathrm{~s})$. The average measuring A-weighted, slow response sound level $\overline{L_{A}}$ for $n$ measurements can be as follows:

$$
\overline{L_{A}}=10 \log \left[\frac{1}{n} \sum_{i=1}^{n} 10^{L_{A i} / 10}\right] .
$$

The sum of squares of the deviations for the measurement results is

$$
s^{2}=\frac{\sum_{n}\left(L_{A i}-\overline{L_{A}}\right)^{2}}{n-1} .
$$

Measuring system consists of: microphone with preamplifier, calibrator of sound pressure levels and sound level meters. There are many factors to be considered when assessing the measurement uncertainty associated with a sound level meter. In this paper it was proposed that the A-weighted steady sound pressure level, $L_{A}$ obtained by using a sound level meter, is given by equation (6) [10]

$$
\begin{aligned}
L_{A}= & \overline{L_{A}}+U\left(\delta_{L_{A}}\right)+U\left(\delta_{a d}\right)+U\left(\delta_{\text {cal }}\right)+U\left(\delta_{\text {res }}\right) \\
& +U\left(\delta_{\text {pres }}\right)+U\left(\delta_{\text {mic }}\right)+U\left(\delta_{\text {time }}\right)+U\left(\delta_{\text {fr }}\right)
\end{aligned}
$$

where:

$L_{A} \quad$ is the unknown A-weighted sound pressure level; $\frac{L_{A}}{L_{A}} \quad$ is the average of measured A-weighted steady sound pressure level; 
$U\left(\delta_{L_{A}}\right)$ is the expanded uncertainty due to the repeatability of $n L_{A}$ measurements;

$U\left(\delta_{a d}\right) \quad$ is the expanded uncertainty due to correction associated with the adjustment of the sound level meter during calibration with a sound calibrator;

$U\left(\delta_{\text {cal }}\right) \quad$ is the expanded uncertainty due to correction associated with the calibration of the sound calibrator;

$U\left(\delta_{r e s}\right)$ is the expanded uncertainty due to the correction associated with the resolution of the display;

$U\left(\delta_{\text {pres }}\right)$ is the expanded uncertainty due to the correction associated with variations in ambient pressure;

$U\left(\delta_{m i c}\right)$ is the expanded uncertainty due to the correction associated with the calibration of the microphone;

$U\left(\delta_{\text {time }}\right)$ is the expanded uncertainty due to the correction associated with the time weighting function (fast or slow);

$U\left(\delta_{f r}\right) \quad$ is the expanded uncertainty due to the correction associated with the A-weighting network.

\subsubsection{Contribution associated with sound field measurements}

One principle underlying this test method is that the reverberant sound fields in the rooms show only small variations with position of measurements in the room. In practice, a certain amount of spatial variance must be tolerated and compensated for by correctly sampling the sound fields. Sound field around the measurement point depend on the distance between the source(s) and the microphone position, the room properties, orientation of sound sources and frequency where the distances between the source and the microphones have to satisfy the relationship [11]:

$$
r \geq \frac{1}{4} \sqrt{\frac{10 A}{\pi}}
$$

where:

$A=$ sound absorption in the room; and

$r=$ distance from the source $r$.

\subsubsection{Contribution associated with the adjustment of the sound level meter during calibration with a sound calibrator, $\delta_{\text {ad }}$}

Before a noise emission measurement is carried out the sensitivity of the sound level meter must be checked using a calibrated sound calibrator and if necessary adjusted according to the sound level meter manufacturer's instructions and the data in the calibration certificate for the sound calibrator.

\subsubsection{Contribution associated with the calibration of the sound calibrator, $\delta_{\text {cal }}$}

ISO/IEC 17025 standard requires that the sound calibrator shall be calibrated "periodically in a manner that is traceable to appropriate standards". This requirement includes the provision of an uncertainty in the calibration supplied by the authorized laboratory. The reported uncertainty is based on a standard uncertainty multiplied by a coverage factor of $k=2$.

\subsubsection{Contribution associated with the resolution of the display, $\delta_{\text {res }}$}

Here the potential error is dependent on the resolution of the sound level meter display. The contribution to an overall uncertainty budget will, therefore, be the same as that assumed for $\delta_{a d}$ which is $\pm 0.05 \mathrm{~dB}[10]$.

\subsubsection{Contribution associated with the calibration of the microphone, $\delta_{\text {mic }}$}

The microphone associated with the sound level meter is calibrated and its sensitivity as a function of frequency is available. It is assumed here that corrections to account for any variation of sensitivity with frequency will be applied to measured data. In this case only an allowance for the uncertainty involved in the calibration of the microphone need to be considered. The microphone uncertainty is based on a standard uncertainty multiplied by a coverage factor of $k=2[10]$.

\subsubsection{Contribution associated with fast or slow time weighting function, $\delta_{\text {time }}$}

$\delta_{\text {time }}$ is a correction that depends on the ability of the sound level meter to provide time averaged data as required by the time weighting functions described as "fast" or "slow" in IEC 61672 part 1:2002. The standard uncertainty is $\pm 0.27 \mathrm{~dB}$ and $\pm 0.22 \mathrm{~dB}$ for fast and slow respectively with normal distributions [10].

\subsubsection{Contribution associated with the A-weighting network, $\delta_{\mathrm{fr}}$}

$\delta_{f r}$ is correction that dependent on the uncertainty associated with the application of the A-weighting function and the standard uncertainty is $\pm 0.07 \mathrm{~dB}$ with a normal distribution [10].

\subsubsection{Combined total standard uncertainty}

The combined total standard uncertainty of the A-weighted and slow response sound level measurements $u\left(L_{A}\right)$ from the $N$ individual contributions is given by equation (8) [2]:

$$
u\left(L_{A}\right)=\sqrt{\sum_{i={ }^{\prime} 1}^{N}\left(c_{i} u_{i}\right)^{2}}
$$

where

$u_{i}$ is the ith uncertainty contribution;

$c_{i}$ is termed a sensitivity coefficient. 
Table 3. Uncertainty budget for sound pressure level measurements of HVAC-Unit.

\begin{tabular}{|c|c|c|c|c|}
\hline $\begin{array}{c}\text { Quantity } \\
X i \\
\text { (unit) } \\
\end{array}$ & $\begin{array}{c}\text { Source of } \\
\text { uncertainty }\end{array}$ & $\begin{array}{l}\text { Probability } \\
\text { distribution }\end{array}$ & $\begin{array}{c}\text { Standard } \\
\text { uncertainty } \\
u\left(x_{i}\right) \\
\end{array}$ & $\begin{array}{c}\text { Uncertainty } \\
\text { contribution } \\
u_{i}(y)=c_{i} u\left(x_{i}\right) \\
\end{array}$ \\
\hline$\delta_{L_{A}}(\mathrm{~dB})$ & $\begin{array}{l}\text { Variation due to } \\
\text { repeatability of } L_{A} \text { for } \\
n \text { measurements }\end{array}$ & Normal & $\frac{s_{r}\left(L_{A}\right)}{\sqrt{n}}$ & $\frac{s_{r}\left(L_{A}\right)}{\sqrt{n}}$ \\
\hline$\delta_{a d}(\mathrm{~dB})$ & $\begin{array}{l}\text { Adjustment of the } \\
\text { sound level meter } \\
\text { during calibration } \\
\text { with a sound } \\
\text { calibrator }\end{array}$ & Rectangular & $\frac{\delta_{a d}}{2 \sqrt{3}}$ & $\frac{\delta_{a d}}{2 \sqrt{3}}$ \\
\hline$\delta_{c a l}(\mathrm{~dB})$ & $\begin{array}{l}\text { Correction associated } \\
\text { with the calibration of } \\
\text { the sound calibrator }\end{array}$ & Normal & $\frac{U\left(\delta_{\text {cal }}\right)}{K_{N, 95 \%}}$ & $\frac{U\left(\delta_{c a l}\right)}{K_{N, 95 \%}}$ \\
\hline$\delta_{\text {res }}(\mathrm{dB})$ & $\begin{array}{l}\text { Correction associated } \\
\text { with the resolution of } \\
\text { the display }\end{array}$ & Rectangular & $\frac{\delta_{\text {res }}}{2 \sqrt{3}}$ & $\frac{\delta_{\text {res }}}{2 \sqrt{3}}$ \\
\hline$\delta_{f r}(\mathrm{~dB})$ & $\begin{array}{l}\text { Correction associated } \\
\text { with the application } \\
\text { of the A-weighting } \\
\text { function }\end{array}$ & Normal & $\frac{U\left(\delta_{f r}\right)}{K_{N, 95 \%}}$ & $\frac{U\left(\delta_{f r}\right)}{K_{N, 95 \%}}$ \\
\hline$\delta_{m i c}(\mathrm{~dB})$ & $\begin{array}{l}\text { Correction associated } \\
\text { with the calibration of } \\
\text { the microphone }\end{array}$ & Normal & $\frac{U\left(\delta_{m i c}\right)}{K_{N, 95 \%}}$ & $\frac{U\left(\delta_{m i c}\right)}{K_{N, 95 \%}}$ \\
\hline$\delta_{\text {time }}(\mathrm{dB})$ & $\begin{array}{l}\text { Correction associated } \\
\text { with fast or slow time } \\
\text { weighting function }\end{array}$ & Rectangular & $\frac{\delta_{\text {time }}}{2 \sqrt{3}}$ & $\frac{\delta_{\text {time }}}{2 \sqrt{3}}$ \\
\hline
\end{tabular}

- $K_{N, 95 \%}$ : the coverage factor for confidence level $95 \%$

- The sensitivity coefficients. $c_{i}$ equal 1.

The expanded uncertainty is obtained by multiplying a combined standard uncertainty, $u c(y)$ by a coverage factor $k$ depending on the desired level of confidence and the type of statistical distribution [2] where:

$$
U(Y)=k u c(y) \text {. }
$$

In cases where a normal (Gaussian) distribution can be attributed to the measurand and the standard uncertainty associated with the output estimate has sufficient reliability, the standard coverage factor is $k=2$ and the assigned expanded uncertainty corresponds to a coverage probability of approximately $95 \%$ [12].

The contributions to the total uncertainty have been summarized in Table 3.

\section{Results and discussion}

The uncertainties of HVAC sound pressure level test for each participant have been calculated. Figure 1 shows the expanded uncertainty contribution for sound pressure level slow response measurement results at $125 \mathrm{~Hz}$ of HBRC acoustic lab. The figure shows that the expanded uncertainty due to time variation of the SPL measurements has a significant influence on the total expanded uncertainty. So effort should be concentrated on reducing the variation of sound pressure level in rooms by selecting suitable positions of the microphone. Also the expanded uncertainty associated with the calibrations for instruments have significant contribution to the total expanded uncertainty. Therefore reducing the expanded uncertainty associated with the calibrations for instruments can be achieved by selecting suitable accredited laboratory with low uncertainty for calibrating the instruments.

The repeatability values, $r$ for the different measurements performed by HBRC acoustic lab have been determined. Also the reproducibility value, $R$ for the measurements of all participating laboratories has been determined. The normalized error, $E_{n}$-value between each laboratory and NIS acoustic laboratory that has lowest uncertainty was evaluated.

The HBRC acoustic lab uncertainty for the A-weighted, slow level for a steady HVAC unit source measurements was $0.98 \mathrm{~dB}$ while the octave band uncertainty varied from 1.09 to $1.67 \mathrm{~dB}$.

The repeatability values, $r$ (i.e. for all 9 frequencies) found on identical test equipment by one operator using the same apparatus within a short time interval is given in Table 4. The HBRC acoustic lab repeatability values, $r$ for the A-weighted slow level for a steady HVAC unit source 


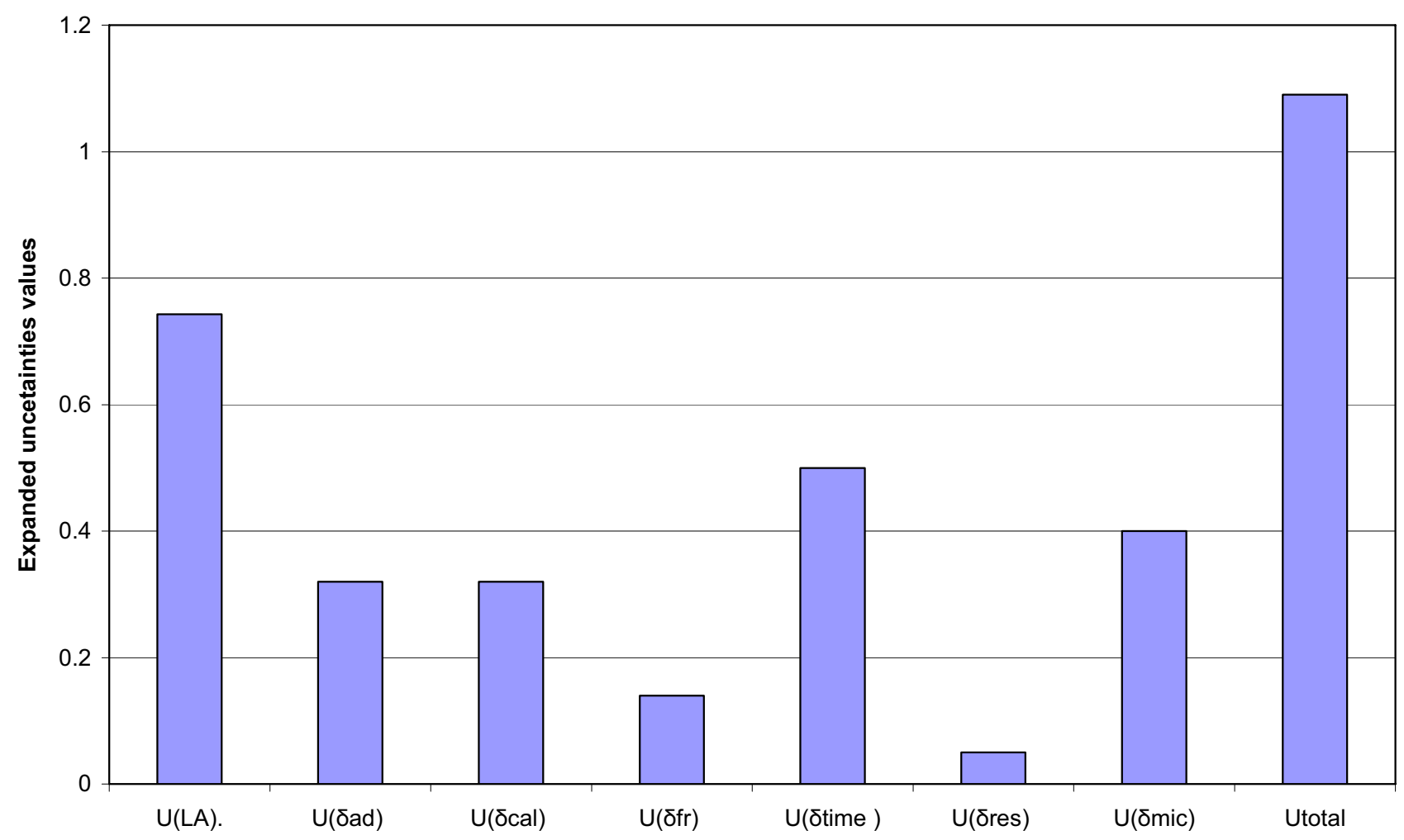

Fig. 1. (Color online) Expanded uncertainty contributions in $L_{A}$ results at $125 \mathrm{~Hz}$.

Table 4. Inter-Laboratory comparisons results indoor sound pressure level measurements of HVAC-Unit.

\begin{tabular}{|c|c|c|c|c|c|c|c|c|c|c|c|}
\hline \multirow{2}{*}{$\begin{array}{c}\text { Measurements in } \\
\text { dBA }\end{array}$} & \multirow[b]{2}{*}{ Lab. } & \multicolumn{9}{|c|}{ Octave band frequency in $\mathrm{Hz}$} & \multirow{2}{*}{$\begin{array}{l}\text { Broad band } \\
L_{A}(\text { in } \mathrm{dBA})\end{array}$} \\
\hline & & 31.5 & 63 & 125 & 250 & 500 & 1000 & 2000 & 4000 & 8000 & \\
\hline$S_{r}$ of HBRC & & 1.75 & 1.43 & 1.16 & 1.16 & 1.57 & 1.96 & 1.27 & 1.21 & 1.33 & 1.05 \\
\hline \multirow{5}{*}{$\begin{array}{l}\text { Uncertainties based } \\
\text { on UE* and } \\
\text { 2XEXP. STDEV } \\
\text { of HBRCs mean } \\
\text { value }\left(U_{\text {total }}\right) \\
\end{array}$} & NIS & 1.40 & 1.02 & 0.85 & 1.14 & 1.15 & 1.22 & 1.20 & 0.82 & 0.97 & 0.75 \\
\hline & HBRC & 1.60 & 1.32 & 1.09 & 1.27 & 1.45 & 1.67 & 1.18 & 1.12 & 1.23 & 0.98 \\
\hline & Luukki & 1.85 & 2.10 & 1.68 & 2.33 & 1.74 & 2.05 & 1.80 & 1.52 & 1.65 & 1.48 \\
\hline & Hman & 1.80 & 2.48 & 1.54 & 2.51 & 2.13 & 2.53 & 2.52 & 1.98 & 1.78 & 1.42 \\
\hline & Eg Cool & 1.81 & 1.75 & 1.82 & 1.98 & 2 & 1.9 & 2.09 & 2.15 & 1.92 & 1.38 \\
\hline \multirow{5}{*}{$\begin{array}{l}\text { Average sound } \\
\text { pressure level. } \\
\overline{L_{A}}\end{array}$} & NIS & 27.80 & 35.50 & 45.70 & 55.20 & 55.20 & 51.80 & 51.60 & 45.80 & 38.60 & 60.10 \\
\hline & HBRC & 27.90 & 35.90 & 46.10 & 55.80 & 55.30 & 51.30 & 51.90 & 45.50 & 38.20 & 60.40 \\
\hline & Luukki & 27.30 & 34.40 & 47.20 & 53.70 & 55.50 & 52.90 & 50.60 & 45.00 & 37.30 & 60.00 \\
\hline & Hman & 26.60 & 34.90 & 46.50 & 53.70 & 54.20 & 53.80 & 51.40 & 46.20 & 37.80 & 59.90 \\
\hline & Eg Cool & 26.30 & 34.80 & 47.20 & 54.50 & 55.70 & 52.40 & 50.90 & 44.90 & 37.40 & 60.20 \\
\hline \multirow[t]{4}{*}{$E_{n}$ re. NIS } & HBRC & 0.05 & 0.24 & 0.29 & 0.35 & 0.05 & -0.24 & 0.18 & -0.22 & -0.26 & -0.24 \\
\hline & Luukki & -0.22 & -0.44 & 0.8 & -0.58 & 0.14 & 0.46 & -0.46 & -0.46 & -0.68 & -0.06 \\
\hline & Hman & -0.53 & -0.22 & 0.45 & -0.54 & -0.41 & 0.71 & -0.07 & 0.19 & -0.39 & -0.12 \\
\hline & Eg Cool & -0.66 & -0.35 & 0.75 & -0.31 & 0.22 & 0.27 & -0.29 & -0.39 & -0.56 & 0.06 \\
\hline \multicolumn{2}{|l|}{$r$ for HBRC } & 4.90 & 3.99 & 3.26 & 4.38 & 4.47 & 4.74 & 3.56 & 3.39 & 3.73 & 2.95 \\
\hline \multicolumn{2}{|l|}{$R$ for all laboratories } & 7.38 & 5.99 & 5.62 & 6.14 & 5.89 & 5.16 & 4.85 & 4.40 & 4.05 & 3.84 \\
\hline
\end{tabular}

* $U_{E}$ is the expanded uncertainty of the instrumentation itself.

was $2.95 \mathrm{~dB}$ while the octave band repeatability varied from 3.26 to $4.9 \mathrm{~dB}$.

Reproducibility values $R$ (i.e. for all 9 frequency bands) found by different apparatus and different operators from 5 different laboratories using the same measuring method for the same HVAC unit sample are given in Table 4. Reproducibility values $R$ between the participating laboratories is 3.84 for the A-weighted slow level for a steady
HVAC unit source while the octave band reproducibility varied from 4.05 to $7.38 \mathrm{~dB}$.

Table 4 shows the corresponding $E_{n}$-values for the 4 labs compared with NIS.

As can be seen this manoeuvre makes good sense for all. When compared with NIS (the test laboratory with the lowest uncertainty) the 4 other Labs get $E_{n}$-values less than '1.0'. The normalized error $E_{n}$-value between HBRC 
acoustic laboratory and NIS acoustic lab was $-0.24 \mathrm{~dB}$ for A-weighted and slow level for a steady HVAC unit source. $E_{n}$-values varied from -0.26 to $0.35 \mathrm{~dB}$ which shown to be satisfactory.

\section{References}

1. ISO/IEC 17025, International Organization for Standardization, General requirements for the competence of testing and calibration laboratories, 2nd edn., (2005)

2. BIPM, IEC, IFCC, ISO, IUPAC, IUPAP, OIML, Guide to the expression of uncertainty in measurement, International Organization for Standardization (Geneva, 1993)

3. S. Sartori, Estimation of measurement uncertainty considerable example, HMD 18th Metrology Symposium (Cavtat, Croatia, 2001)

4. Dr. H.S. Nielsen, Determining Consensus Values in Interlaboratory Comparisons and Proficiency Testing, NCSL International Workshop and Symposium (2003)

5. ISO/IEC, Conformity assessment - General requirements for proficiency testing (2010)
6. ISO 5725-6, International Organization for Standardization, Accuracy (trueness and precision) of measurement methods and results - Part 6: Use in practice of accuracy values (1994)

7. ASTM E 1574, American Society for Testing and Materials, Standard Test Method for Measurement of Sound in Residential Spaces, 98 (2006)

8. ASHRAE, American Society of Heating, Refrigerating and Air-Conditioning Engineers, Recommended Procedure for Measuring the HVAC System - Induced Noise in a Room (Draft \#10) (2007) www.enoisecontrol.com

9. ASHRAE, American Society of Heating, Refrigerating and Air-Conditioning Engineers, Fundamentals Handbook (SI) (1997), Chap. 7

10. R. Payne, Uncertainties associated with the use of a sound level meter, NPL Report DQL-AC 002, 2004

11. ASTM E90-04, Standard test method for laboratory measurement of airborne sound transmission loss of building partition and elements

12. EUROLAB, European Federation of National Associations of Measurement. Testing and Analytical Laboratories, Measurement Uncertainty in testing, Technical Report $1 / 2002,2002$ 